\title{
Construction of New Model for Innovative Talents Training
}

\author{
Chenguang Yan, Yujing Liu, Luke Wang \\ College of Science \\ Hebei University of Science and Technology \\ Shijiazhuang, China
}

\begin{abstract}
Based on the construction of the present mode for talent training, the effects and significations of mathematical contest in modeling of training for practical talents are described. With the help of variance analysis method, the role of mathematical contest in modeling of students' innovative ability is analyzed according to the dates from the questionnaire. Viewing the result, it was found that students' ability to reason and innovate were effectively exercised and improved with the experience of mathematical contest in modeling. Therefore, the new training mode based on mathematical contest in modeling is of significant importance in the cultivation of students' innovative ability.
\end{abstract}

Keywords-mathematical contest in modeling; innovative ability; variance analysis

\section{INTRODUCTION}

In the 1990s, China began to pay attention to the diversification of the talent training model. In 2007, China put forward the strategy of strengthening country by talents. In the same year, "China Undergraduate Mathematical Contest in Modeling (CUMCM)" was listed in discipline competitions funded by the Ministry of Education. The importance and influence of this contest has been continuously enhanced, and the scale has expanded year by year.

Since the promulgation of the National Medium and Long Term Education Reform and Development Plan (2010-2020), research on the training mode of practical talents has been a hot issue in the field of higher education. ${ }^{[1]}$ It has become a key issue that how to integrate innovative talents with local economic development. ${ }^{[2]}$ Meanwhile, with the goal of cultivating the ability to solve practical problems using mathematical theories and methods, innovative education has become a hot topic in the reform of mathematics teaching. ${ }^{[3]}$ Innovation is the first driving force for development, $\mathrm{Xi}$ Jinping pointed out in his report at 19th CPC National Congress. To accelerate the construction of innovative country, we need to target the world's science and technology frontiers, advocate innovation culture, and cultivate innovative talents. Therefore, how to cultivate a large number of innovative talents is one of the most urgent issues. ${ }^{[4]}$ As a frontier for cultivating talents and implementing quality education, colleges and universities shoulder the heavy responsibility of cultivating innovative talents. ${ }^{[5]}$

There were lots of researches on the relationships between

This article is the result of Research and practice Project of Teaching Reform in higher Education of Hebei province, project number: 2018GJJG195.
MCM and talent cultivation. ${ }^{[6]}$ Germany first enacted mathematics education standards in 2003, with particular emphasis on the position and role of MCM capabilities in macroeconomic education. ${ }^{[7]}$ In 2006, United States established National Mathematical Committee, which highlighted the important role of modeling capabilities in the development of learning and innovation capabilities. ${ }^{[8]}$ Meanwhile, France established "Animath" and promoted the application of mathematics and MCM, especially in engineering and industry. ${ }^{[9]}$ In summary, developed countries have given full attention to the role of MCM in cultivating practical talents.

General speaking, mathematics plays an important role in cultivating students' innovative and exploring spirit, while mathematical contest in modeling (MCM) plays an irreplaceable role in cultivating students' ability to innovate. ${ }^{[10]}$ Form the viewpoint of MCM, innovation ability is the practical basis of problem solving. Excellent innovation ability are not only the characteristic of innovative talents, but also an important difference between innovative and traditional talents. The ability of analogy analysis offers foundation for the innovative talent to analysis problems by applied mathematics, and insurance the clarity and efficiency of thinking in face of unfamiliar problems. ${ }^{[11]}$

\section{CONSTRUCTION AND OPERATION OF THE FOUR-IN-ONE Mode of PRACTICAL TALENT TRAINING}

Hebei University of Science and Technology is an important force for cultivating practical talents with local economic development. With the Beijing-Tianjin-Hebei collaborative strategy, Hebei Province faces the challenge of industrial structure upgrading and economic transformation. This requires not only high-end professional and technical personnel, but also a large number of innovative and practical talents who are proficient in mathematics application in engineering. In view of this, starting from 2012, we began new exploration in the talent training mode, with mathematics modeling and its application as the main focus and foundation, and constructed a four-in-one training mode of "knowledge, practice, application and ability". After tracking the four consecutive students, the analysis shows that the four-in-one training mode of "knowledge, practice, application and ability" has a significant effect on the cultivation of innovative and applied talents. 
In 2012, by the help of school's resources based on the Key Discipline Platform of Hebei Province, the Department of Mathematics began to build the now mode of talent training in two specialties: Mathematics and Applied Mathematics, Information and Computational Sciences. That is the so-called four-in-one talent training mode based on mathematical modeling, consisting of four modules: knowledge, practice, application, and ability (as shown in Figure 1). The main innovations are as follows.

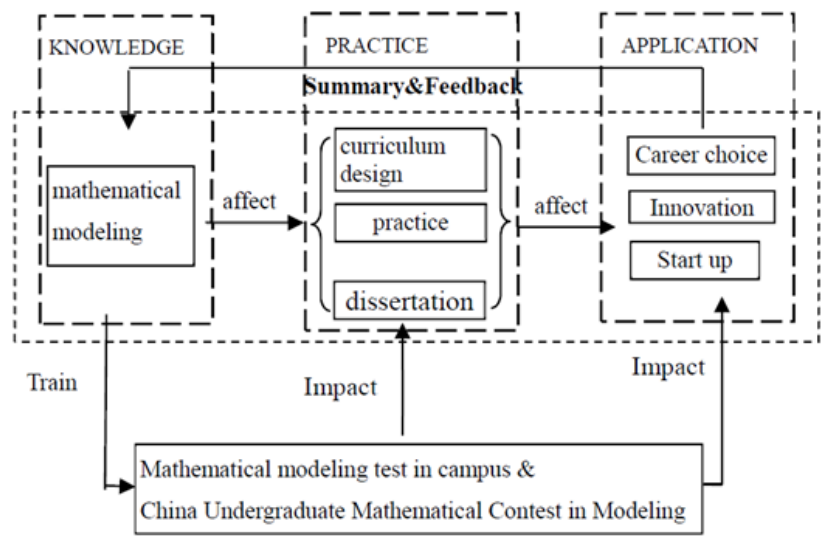

Fig. 1. The four-in-one talent training mode of "knowledge, practice, application and ability"

- Theoretical knowledge teaching reform. First, update the theoretical knowledge of the classroom and design exploratory experiments to produce multimedia courseware that is compatible with the new theoretical knowledge system. For the applied mathematics major, focus on building the foundation of its mathematical application, introducing the application of mathematical modeling in economic management, mechanical manufacturing, electrical automation, materials science, environmental engineering, biomedicine, etc. in classroom teaching, starting from the case design method And content, causing students' resonance and interest in learning; For the majors of information and computational science, we will improve our knowledge system in the field of big data and scientific computing, and develop the ability of students to develop and design languages such as $\mathrm{C}$ and MATLAB in the classroom. Secondly, improve the evaluation and evaluation methods of the series of mathematical modeling courses, and adjust the "heavy theory and light application" mode based on theoretical assessment to the "theoretic and application-oriented" approach based on application assessment, focusing on the ability to solve practical problems. Assessment. Two modules of theoretical test and application exploration are set up in parallel in the exam.

- Multiple forms of competition modules. Establish a modeling association among first-year students, select modeling experience and award-winning old team members to be responsible for the operation and training of the association, select experienced instructors to regularly attend the association lectures; select students from the first and second grade students to participate in the school construction Model competition, those with excellent results participate in the national MCM in September each year.

- Innovative exploration of the practice model. Integrate curriculum design, personalized education, production internships, graduation thesis and other practical aspects with mathematical modeling teaching and competition. Encourage students to choose mathematics modeling in the course design, personalized education and graduation thesis to conduct research; establish a team of instructors with mathematical modeling and graduation thesis, implement the mentor responsibility system, and guide teachers and students The combination is fixed so that students receive a longterm guidance from a high-level instructor.

- The cultivation of application ability. Based on the distinction between creative application and imitation application, the training of students focus on applying mathematical modeling and knowledge in job selection, innovation and entrepreneurship (including college students' innovative training programs, etc.), with particular emphasis on cultivating students' initiative. And the ability to apply mathematical modeling knowledge innovation to solve practical problems and to analyze and solve problems, all of which are the goals of applied talent development.

\section{DATA AND ANALYSIS}

Since 2012, the four-in-one practical talent training model has been put into practice for 7 years. On the whole, the results are more significant. The following effectiveness analysis is mainly based on the performance of the internal students and the off-campus, for the former, including the scores of various subjects and the results of the graduate entrance examination, for the latter, including the performance in employment and innovation. Meanwhile, a questionnaire is designed to collect and analysis the performance. The specific analysis is as follows.

\section{A. Analysis of variance of internal students' academic performance}

We calculated the scores of some subjects, and divided them into the control group (student who did not participate in the MCM) and the experimental group (participated in the MCM). Then five subjects were selected. The results showed that the control group and the experimental group had significant differences in the scores of the four courses. The results are as follows.

From the above table, there are statistically significant differences in the scores of two group students. Especially, in some theoretical subjects, such as equations of mathematical physics, life insurance actuarial. While, in the case of some practical course, for example experimental design of optical physics, there is no statistically significant differences. There were two reasons for this. Firstly, the main aim of mathematical modeling is to nurture student's talent in the application of mathematical knowledge to analysis and solve 
the practical problem, although there are lots of practical knowledge in course. Secondly, the sample of this course is relatively small to get the statistical result and significance. This is an indication that mathematical modeling course and contest have to adapt to the new situation-pay more attention to the ability to practice and operate.

TABLE I. ANALYSIS OF VARIANCE ANALYSIS RESULTS OF DIFFERENT SUBJECTS IN THE CONTROL GROUP AND THE EXPERIMENTAL GROUP

\begin{tabular}{|l|c|c|c|c|c|}
\hline Subject & $\begin{array}{c}\text { Mean } \\
\text { Square }\end{array}$ & $\begin{array}{c}\text { Intra- } \\
\text { Group } \\
\text { Mean } \\
\text { Square }\end{array}$ & $\begin{array}{c}\text { Value } \\
\text { Of F }\end{array}$ & $\begin{array}{c}\text { Value } \\
\text { Of } \boldsymbol{p}\end{array}$ & $\begin{array}{c}\text { Significant } \\
\text { Difference }\end{array}$ \\
\hline $\begin{array}{l}\text { Finance } \\
\text { Engineering }\end{array}$ & 282.7 & 61.8 & 4.57 & 0.075 & YES \\
\hline $\begin{array}{l}\text { Life insurance } \\
\text { actuarial }\end{array}$ & 432.17 & 57.34 & 7.54 & 0.031 & YES \\
\hline $\begin{array}{l}\text { Computational } \\
\text { physics }\end{array}$ & 144.5 & 27.583 & 5.239 & 0.062 & NO \\
\hline $\begin{array}{l}\text { Equations of } \\
\text { Mathematical } \\
\text { Physics }\end{array}$ & 311.21 & 37.63 & 8.27 & 0.028 & YES \\
\hline $\begin{array}{l}\text { Basic of } \\
\text { optoelectronic } \\
\text { technology }\end{array}$ & 312.5 & 16.92 & 18.47 & 0.005 & YES \\
\hline $\begin{array}{l}\text { Experimental } \\
\text { design of optical } \\
\text { physics }\end{array}$ & 45.125 & 10.458 & 4.315 & 0.083 & NO \\
\hline
\end{tabular}

From the above table, there are statistically significant differences in the scores of two group students. Especially, in some theoretical subjects, such as equations of mathematical physics, life insurance actuarial. While, in the case of some practical course, for example experimental design of optical physics, there is no statistically significant differences. There were two reasons for this. Firstly, the main aim of mathematical modeling is to nurture student's talent in the application of mathematical knowledge to analysis and solve the practical problem, although there are lots of practical knowledge in course. Secondly, the sample of this course is relatively small to get the statistical result and significance. This is an indication that mathematical modeling course and contest have to adapt to the new situation-pay more attention to the ability to practice and operate.

\section{B. Achievements in the Graduate Entrance Examination}

At present, a total of 137 valid questionnaires have been collected, the analysis is as following.

Among the respondents participated in MCM, $46.51 \%$ choose "social and administrative type that required certain innovative ability" as the ideal work, while the corresponding proportion of respondents who did not participate in the MCM was $42.8 \%$. More than half of the respondents believe that "participating in MCM is helpful for finding a job", nearly $30 \%$ of the respondents believe that "participating in MCM is very helpful for finding a job"; the two ratios of respondents participated in MCM are $40 \%$ and $45 \%$ respectively.

$48 \%$ of respondents believe that MCM "could solve practical problems rather than just calculations", while $46 \%$ of respondents believe that MCM "could improve teamwork ability", and nearly $83 \%$ believe that participating in MCM are helpful in improving innovative ability. Beyond these, respondents believe that MCM could help them greatly in improving the ability in analysis, problem-solving and teamwork".

Meanwhile, career choice is affected by many factors, and it is difficult to evaluate the ability to innovate. Meanwhile, the data above is subjective, all of results show that MCM has a greater shaping and influence on students' employment and innovation.

\section{CONCLUSION}

The four-in-one training model constructed in this paper shows more advantages, and its main innovations are:

(1) Organically combining the objectives of talent training with curriculum systems and MCM to develop students' practical ability and innovative thinking.

(2) With the teaching of theoretical knowledge, the training of competition ability and innovation ability, improving of practical ability as starting point, focusing on mathematical modeling courses and MCM.

(3) Constructing virtuous circle of "promoting competition by theory, practice by competition, and innovation by practice", comprehensively build all-round development of students' abilities.

After nearly seven years, the training model has achieved remarkable results. Recent years, many students have successively past the postgraduate exam of some 985 and 211 universities. Many outstanding students have been recruited by China Unicom, Gree Electric Appliances, Great Wall Motor and other top 500 companies, showing that the students not only have strong theoretical research capabilities, but also have strong competitiveness in application development and employment.

Of course, there are also many areas where the training model needs to be improved. For example, efforts should be made to cultivate students' practical ability and to cultivate and train students' entrepreneurial thinking and ability. In fact, how to adapt to the trend of the country's "popular innovation, entrepreneurship", combine local economic development, especially the coordinated development of Beijing-TianjinHebei and the goal of training talents in schools, and create a new talent training model, always at every higher level. The most practical problem facing educators can be expected to further explore this aspect of this training model and follow-up research.

\section{REFERENCES}

[1] Gu Yongan, Lu Zhenglin. Thoughts and Suggestions on Promoting Applied Undergraduate Education in China. Modern Education Management, 2011 (12), pp: 37-41. (In Chinese)

[2] Liu Zhifeng, Wang Xiaoyu. On the Cultivation Orientation and Construction System for practical Talents in Local Undergraduate Universities. Educational Research, 2012(12), pp: 67-71. (In Chinese) 
[3] Duan Peichao, Zhang Chunxiao, Gao Yongxin. Cultivating Engineering practical Talents through Mathematical Modeling. Mathematics Learning and Research, 2014(13), pp: 4-7. (In Chinese)

[4] Wei Chunyan, Research on Teaching Reform of Advanced Applied Mathematics Based on Mathematical Modeling. Heilongjiang Education (Theory and Practice), 2016(11), pp:67-68. (In Chinese)

[5] Wang Zhuo Exploring the Establishment of Innovation Consciousness in Mathematical Modeling. China New Telecommunications, 2017, 19(10). (In Chinese)

[6] Bai Yiqing. Analysis of College Students' MCM and Cultivation of Innovative Ability. New Campus: Reader's Edition, 2016(6). (In Chinese)

[7] XU Bin-yan, On Mathematical Competence Model in Mathematics Education Standards in Germany. Courses, Teaching Materials and Teaching Methods, 2007 (9), pp: 84-87. (In Chinese)

[8] Xiao Yi, Gao Jun. Analysis of the Final Report of the National Mathematical Committee of the United States. Mathematics Communications,2008(15), pp:5-10. (In Chinese)

[9] M. Andler, E. Ghys, V. Kleptsyn, D. Schleicher, S. Tabachnikov. International Mathematical Summer School for Students. Newsletter of the European Mathematical Society. 2011(81), pp:12-14.

[10] Song Kehui, Tian Shenghui, Peng Qingwen. The Knowledge, Ability and Quality Structure and Its Cultivation of the practical Talents. Higher Education Research, 2012(7), pp:94-98. (In Chinese)

[11] Zhou Ligang, Chen Huayou. Research on the Training Mode and Practice of Applied Mathematics Talents Based on International Mathematical Contest in Modeling. Journal of Hubei University of Science and Technology, 2016(12). (In Chinese) 